\title{
La libertad del medio y la construcción de la información próxima en la política
}

The freedom of Media and the construction of the near information in politics

H. Miluska Sánchez Gonzales

Profesora da Universidad de Sevilla

Correo eletrónico: misago@us.es

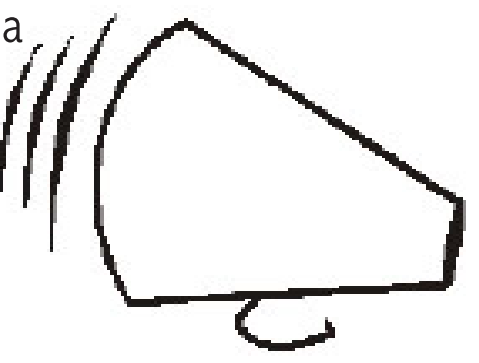

Resumo

0 princípio relacional da política com a informação factual se sedimenta no uso da técnica, na estrutura e no processo como sistemas que colhem, transmitem, comunicam e observam uma sequência de condutas no indivíduo. São modos de fazer política e de trasnferi-la de acordo com sua capacidade de mobilizar o individual ou o coletivo e que, por sua vez, dá lugar a comportamentos espetaculares. Se, da liberdade do meio em construir uma informação por meio de paradigmas adaptados à compreensão humana de processos metacognitivos emocionais e de inferência, de acordo com ssua vivências e singularidades.

Palavras-chave: política, periodismo, emoção, informação, meio.

La interacción informativa, estructura y proceso

E1 Periodismo y la política confluyen en el principio relacional de los hechos percibidos y de la información por medio de la técnica de actuación: los medios de comunicación. Implicamos al sujeto espectador como actuante del hecho que, a su vez, ha sido moldeado por otros agentes operatorios dentro de un proceso central donde el mensaje adquiere valor, de acuerdo a la situación en que se establezca y al tiempo $\mathrm{y}$ espacio en el que se halle.

La información periodística nace a raíz de la percepción de los hechos y se distingue por ser una información de actualidad con respecto a las demás ciencias, según el grado de especialización.

La política como estructura ${ }^{1}$ ha generado su propio modo de actuación y de organización a lo largo de la historia. Ha ido remplazando unas por otras debido al resultado de los cambios socioculturales y técnicos. Además, ha aplicado un modelo inspirado en la cibernética, con el criterio de ser comprendida como un sistema, como una “organización compleja que recoge y transmite información, genera actividades y controla resultados. Tiene su autonomía, pero está vinculada a un entorno del que recibe información y sobre el cual, a su vez, actúa" (Vallés, 2002: 48).

La información periodística se instaura como una empresa al servicio del interés socio económico y político, de ahí que pierde el sentido de la verdadera función. Los hechos se espectacularizan reduciendo los aspectos interpretativos en aras de los más emotivo ofreciendo una realidad especializada del conocimiento.

La información especializada ${ }^{2}$ establece sus relaciones teniendo en cuenta el ciclo del acontecimiento porque cualquier cambio de un periodo incide en la alteración del otro. El avance de la ciencia está ligado a la especialización, cada una de ellas va creando su propia terminología (Fernández y Esteve, 1996:14).

La información periodística especializada contribuye a establecer un trato en busca de conciliaciones sociales con contenidos científicos y técnicos ante el aislamiento de las masas. Aborda diferentes géneros y
${ }^{1}$ La estructura política es concebida por algunos autores de modo similar a una "máquina", para otros, la imagen es adoptada por el "organismo viviente. Para subsistir va dotándose de órganos que ejercen diferentes funciones. Debe adaptarse al medio en que habita, del que obtiene los medios de subsistencia y al que aporta algo que justifique supervivencia". La tercera y última se refiere al mercado "-como el que tiene lugar en la plaza de una aldea- es un ámbito de encuentro, basado en un conjunto de hábitos y reglas" (Vallés, 2002: 48).

${ }^{2}$ El estudio de las áreas de la información especializada ha sido abordado por diversos autores, entre ellos: Martínez Albertos, Fernández del Moral, Esteve Ramírez, Concha Fagoaga 
${ }^{3}$ Un ejemplo de política como proceso se ve claramente cuando "un grupo de vecinos bloquea por la fuerza el acceso a una planta incineradora de basuras instalada en las cercanías de su barrio se unen a la protesta y se manifiestan ante el ayuntamiento. Ante la dimensión de la protesta, el alcalde abre una investigación sobre la actuación de la policía e invita a los vecinos a formar una comisión de estudio sobre el problema de la incineradora. Los vecinos se dividen entre quienes aceptan la invitación del alcalde y los que la rechazan. El partido de la oposición municipal toma contacto con los vecinos. La empresa parietaria de la incineradora amenaza con despedir a sus trabajadores si no se permite el funcionamiento normal de la planta. Los trabajadores acuden al sindicato para que se garanticen sus puestos de trabajo. Algunos grupos ecologistas ayudan a los vecinos a documentar su protesta con datos relativos a la contaminación del barrio y les prestan apoyo organizativo. Los medios de comunicación se hacen eco del conflicto, etc. Cualquier episodio político se caracteriza por la intervención en cadena de una serie de actores- individuales y colectivos- por la adopción de formas diversas de intervención" (Vallés, 2002: 244).

\footnotetext{
${ }^{4}$ Por otra parte tenemos que hablar de la convivencia entre periodistas y políticos con "cierto tipo de promiscuidad que puede imponer otro tipo de barreras a la información" (Bezunartea y Canga, 1989:11).
}

${ }^{5}$ Los políticos cuidan al sujeto receptor porque son sus electores, de ahí que controla la información que lo pueda perjudicar a través de su portavoz.

${ }^{6}$ Sobre las restricciones de la información política se puede abordar tres casos: El primero corresponde a las limitaciones de las organizaciones periodísticas, el segundo al control político sobre el flujo de información y el tercero versa sobre las influencias y abusos de poder (Bezunartea y Canga, 1989:13-16). estilos en el análisis de los hechos estimando los temas de mínima especialización. Actividad encausada en el proceso informativo a partir de la recolección de los datos específicos hasta la transmisión de los mismos. Estructura informativa que analiza los hechos reales haciendo uso de las diferentes especialidades del saber, con el fin de ir penetrando en las motivaciones de la audiencia por medio de un mensaje sencillo, coherente e interesante (Fernández y Esteve, 1996:14,93, 100).

Los hechos informativos son en muchos casos instrumentos de influencia y de persuasión a través de canales especializados. En el proceso de lance de la información política, el medio "constituye el sistema nervioso de toda unidad" (Jáuregui, 1989, pp. 70, 71) que comunica y transmite información.

Cuando se analiza la política, además de estructura como proceso $^{3}$ se observa una sucesión de "conductas individuales y colectivas que se encadenan dinámicamente". Desde esta perspectiva se atiende a los comportamientos de los diversos individuos examinando sus motivaciones y su participación (Vallés, 2002: 46).

El sistema político se corresponde con el del Periodismo en tanto que, realiza distintas funciones desde la recepción de los mensajes en forma de noticias, demandas o apoyos a actores, hasta el grado de aceptación de las mismas dentro de un contexto. Encarta y comprueba la información con el ideario y los valores sociales para luego emitir una disposición de "intervención en forma de política pública". La intención se pone de manifiesto porque incide en la realidad (Vallés, 2002: 48,49).

La información de los hechos es crucial en la vida política, los políticos la conducen con suma atención dentro de lo factible. Desde los últi- mos diez años podríamos decir que la política ha sido él cuerpo celeste de los medios, pues, representaba la esperanza de una vida en democracia, un sistema participativo donde la libertad de expresión primaría ${ }^{4}$ (Bezunartea y Canga, 1989:11).

La información política se reviste de ciertas peculiaridades y se construye considerando en primer lugar, la naturaleza de los acontecimientos que trata el propio periodista y por otro, los que proporcionan dichas noticias, es decir, transmite hechos que una tercera persona dice que ha ocurrido y donde él no ha estado presente. Son noticias totalmente programadas a las cuales no se puede acceder de forma directa y están relacionadas con las opiniones. En segundo lugar, se encuentra vinculado con la actitud de los personajes que proporciona la noticia, es decir, los políticos ${ }^{5}$ (Bezunartea y Canga, 1989:14).

Las cuestiones plantean distintos escenarios donde periodistas y políticos actúan y del otro lado, la audiencia. Se establecen límites informativos entre el primer y segundo agente. Análisis que se ve anclado en ciertas restricciones ${ }^{6}$ de la información política y que a su vez, producen rechazo por parte del sujeto receptor (Bezunartea y Canga, 1989:13-16).

Durante varios años la realidad ha sido una de las preocupaciones de los medios, sin embargo hoy se entiende que el Periodismo más que intermediario de realidades es constructor de ella. La noticia tradicional se demarcaba por el "qué de los hechos" y actualmente se centra más en el quién. Se trata de textos periodísticos que adquieren categoría de interés por las declaraciones del personaje que las emite (Herrero, 1997: 45).

Pues, el proceso de la información política se torna en la identifi- 
cación del personaje político, por su comportamiento individual o colectivo. Busca al individuo en si mismo y lo hace protagonista por su accionar con el fin de captar la atención del sujeto receptor.

Todo cambio incide en el perfeccionamiento, en la aparición de órganos y en la unión de estructuras diferentes. Cuanto más se avance hacia "la especialización de la función política, más se progresa en la definición de un ámbito en el que el sujeto individual es actor político $y$, en cierto modo, se emancipa y se libera de una situación en la que persiste la confusión entre dependencias económicas, culturales y políticas" (Vallés, 2002: 74).

Cada individuo vive la actividad política de forma diferente, con mayor grado de fuerza en la "dedicación y especialización en la conducta", lo que ha llevado a definir el perfil de los actores políticos individuales. En cuanto a la intensidad, existen diversos criterios de acción política que, por lo general es bastante escasa, sin embargo nosotros detectaremos la especialización que en cierta medida se refiere a la división del trabajo político. Citaremos de forma breve: los inactivos, los votantes, los comunicadores, los activistas locales, los voluntarios sociales: actividades ecologistas y de solidaridad, los militantes y los activistas totales (Vallés, 2002: 310, 311).

La política es un modo de acción social, de ahí que se orienta en el hombre como actor político dentro de una comunidad. Leyes que se unen como "expresiones" de tipo socio-político. "El individuo es un animal político porque vive en una comunidad y es político porque debe tener en cuenta los principios, valores, normas y rituales sociales de ese espacio común para ser hombre de Estado, para persuadir a sus ciu- dadanos en la Asamblea" (López y Guervós, 2000: 36).

El periodista ha de estar formado y familiarizado con las técnicas propias del Periodismo y con sus especializaciones sabiendo valorar los hechos y evitando distorsionar la realidad en el momento de informar. Ha de cumplir su función de intermediario del mensaje, así como de utilizar un lenguaje común y peculiar de una narración periodística.

La información política tendrá que ser de interés para el ciudadano, es decir, próxima al comportamiento del actor político individual o colectivo como elemento indispensable del proceso metacognitivo ${ }^{7}$ e inferencial abductivo ${ }^{8}$ de la información. Significa estudiar el problema y ver el tratamiento de un hecho noticioso a partir de procesos mentales del individuo donde las unidades emotivas adquieren protagonismo dentro de las necesidades mediales.

La escena de la información política.

El contexto actual se caracteriza por la inminente información que reconoce los procesos de aculturación y al medio como protagonista. Ámbito comunicativo que constituye el campo de aprehensión social donde se halla el fenómeno de lo espectacular dentro de un escenario representativo que presenta mundos probables como posibles.

Al referirnos a lo espectacular nos lleva a reconocer tres distintas concepciones sobre el término en cuestión. El primero nos remite a un significado "técnico" que utiliza reglas codificadas y lenguajes especiales, los cuales son personificados en ciertos espacios buscando la adhesión del público o espectador. El intento del productor y del espectador y su mutuo reconocimiento parece ser la condición sociológica para la atribución del significado
7

L a

met a cogn i c i ó n $\begin{array}{lllllllll}\mathbf{i} & \mathbf{n} & \mathbf{c} & \mathbf{o} & \mathbf{r} & \mathbf{p} & \mathbf{o} & \mathbf{r} & \mathbf{a}\end{array}$ componentes como la conciencia, el control y la autopoiesis. Trata la intencionalidad como "propiedad de la activación mental por el cual ésta se remite siempre a un objeto distinto de ella misma" (Mayor, Suengas y 
${ }^{9}$ Dentro del proceso evolutivo del cerebro primitivo surgieron "los centros emocionales que millones de años mas tarde dieron lugar al cerebro pensante o neocortex". Hecho que supone que el cerebro emocional sea anterior al racional y a su vez, éste sea "una derivación de aquel, revela con claridad las auténticas relaciones existentes entre el pensamiento y sentimiento" (Goleman, 1997, p. 29, 52).

${ }^{10}$ Los actores políticos han de conocer tres cataduras que modifica la conducta del receptor: su aspecto cognitivo, afectivo y volitivo: "cómo piensa obre nuestro mensaje, cómo lo valoran emocionalmente y cómo se disponen a actuar en consonancia con él" (López y Guervós, 2000, p. 98).

${ }^{11}$ El claro ejemplo de una acción política individual que no suele ser considerada es el pago de los impuestos. Sin embargo, la observación fiscal como negativa ante el hecho de cumplir con sus obligaciones tributarias es una acción común dentro de un comportamiento político porque discrepa de la "política gubernamental". No pretendemos abordar determinadas conductas desde un punto de vista moral e individual, "estamos tratando del ámbito de lo público, del terreno de la interacción social y de la participación comunitaria en la formulación del interés colectivo" (Vallés, 2002: 315). técnico, circunscrito a la palabra espectáculo. En su segunda acepción emplea la palabra de espectáculo y de espectacularización en todas aquellas técnicas que permitan captar la atención y comunicar hechos teniendo como base los sentimientos. El tercero y último se aplica a todo el "campo de observación o de escucha de un actor social; la palabra espectáculo se hace casi sinónimo de vida o de naturaleza" (Bechelloni, 1990:59).

La información espectacularizada desde sus inicios se ha ido desarrollado en las diferentes disciplinas en relación con la sociedad. La ciencia del Periodismo lo abstrae a su campo utilizando el sistema relacional, de esta forma se constituye como elemento dentro del quehacer periodístico inmerso en las distintas áreas a través de su técnica.

La espectacularización en el Periodismo halla sus bases en la historia del día a día y se intensifica en razón de la información sobre la vida diaria de las personas, en su proximidad y cercanía de este, anclado en experiencias de inferencia abductivas emocionales.

Reconstruir y representar la interacción de una estructura receptiva dentro de un contexto sociopolítico y cultural, nos lleva a reconocer y observar el desarrollo de diversos tipos de comportamiento comunicativo por medio de dos mentes que interactúan y que nos ayudan a construir nuestra vida: la "mente racional" (de la que solemos ser conscientes), y la "mente emocional" como aquel conocimiento impulsivo, poderoso y a veces ilógico ${ }^{9}$. No obstante, el cerebro emocional se halla inmerso en el razonamiento, pues son importantes dentro del ejercicio de la razón. (Goleman, 1997, p. 29, 52).

El actor político ${ }^{10}$ con el fin de lograr la adhesión del ciudadano apela a la emotividad y a la co- munión en torno a los valores del sujeto receptor, no interviene como personaje famoso, sino que trata de identificarse con el hombre de la calle sobre su entorno próximo e inmediato.

En la política, el hecho de la escena es hoy una herramienta para la acción porque permite ejercer de forma eficaz. La presencia de los medios audiovisuales caracteriza este proceso modificando el tratamiento de las noticias de actualidad política llevándola a pautas donde se incide en la personalización, espectacularidad y simplificación (Vallés, 2002: 54,296).

La acción política tiene diversas maneras de actuar que va desde "lo menos perceptible a lo más espectacular". Todo hecho político individual desemboca en una acción colectiva, por ello es importante analizar la determinación del individuo en la elección de respuestas a ciertas incitaciones de su ambiente, según sus experiencias ${ }^{11}$ (Vallés, 2002: 315).

Todo acontecimiento político se explicita como modos de "hacer política" 12 que entra en conflicto con algunos valores dominantes. Nos referimos a las formas no convencionales de acción y reacción asociadas a demandas de quienes dan poco crédito a la eficacia de las formas convencionales. Se trata de conductas asociadas a modos de resistencia pacífica hasta comportamientos violentos. Estás actividades están "ligadas a su espectacularidad mediática: formar cadenas humanas, ocupar lugares de gran visibilidad (monumentos, puentes, grúas), etc.”. Logran la repercusión deseada según la difusión del hecho por los medios de comunicación (Vallés, 2002: 232,324).

Dicho esto, es necesario avanzar hacia procedimientos de transcodificación relativos al lenguaje. 
Planteamos el paradigma espectacular como aquel procedimiento códico del sistema lingüístico que nos ayuda a comprender y analizar la comunicación humana a nivel metacognitivo.

La espectacularización periodística multiplica su resonancia conmoviendo a la sociedad y por consiguiente al receptor. Se impone una necesidad vital de representar una realidad interpretada que depende de los hechos. No obstante, acomoda el lenguaje con elementos emotivos según el medio y a exigencias de su audiencia.

Se trata del paradigma códico de lo espectacular a través de lo emotivo en el Periodismo. Se encuentra determinado por el impacto que causa en el sujeto receptor y por los beneficios que le brinda al productor, en este caso, los medios de comunicación. Sucesión de códigos establecidos a partir de las vivencias del individuo y que obedecen a la presencia simultánea de diversos subcódigos con el fin de producir un mensaje.

Se trata de emplear estrategias que estimulen al individuo por medio de acciones enmarcadas que propicien su adhesión ante la relación íntegra de los sujetos operatorios que emiten el mensaje, nos referimos al código del Periodismo emotivo $\mathrm{CPE}^{13}$. Paradigma que nos permitiría trabajar con "los estados del individuo, con el fin de conocerlo y de conseguir su preparación en torno a su acción/reacción sobre la información estimulada" (Sánchez, 2006, p. 368).

Distraemos al sujeto utilizando una información emotiva que lo disipe de la rutina teniendo en cuenta la interactuación cognitiva mental de su entorno social, con los procesos mediales. Proceso energético que se convierte en información y nos conduce a la retroalimentación. Ello supone traducir al hombre como agente dependiente de los estímulos externos, los cuales logran determinar su conducta.

Estos flujos informativos nos conducen a reconocer la presencia de un activismo ${ }^{14}$ cultural denominado como Periodismo emotivo. Da inicio a una nueva etapa dentro de dicha ciencia utilizando un lenguaje y paradigma códico según las necesidades de su audiencia. Su puesta en práctica le permite establecer un repertorio comunicativo a partir de la sistémica y de las teorías propias de las Ciencias Sociales que llevan a identificar el elemento "emotivo dentro de la ciencia del Periodismo" como parte de la estructura informativa de forma y contenido, y determinado por el sujeto receptor (Sánchez, 2006: 176, 365-371).

El Periodismo emotivo surge de la relación entre la ciencia del Periodismo y el fenómeno de la emotividad, arraigado a su vez, en la ciencia de la Psicología fenomenológica. Procedimiento sistémico de interpenetración ${ }^{15}$ que ha determinado un activismo periodístico de forma y contenido.

El periodista tendrá que traducir la experiencia humana en información y percepción periodística a través de su conciencia cognitiva, del estado mental y de las funciones que realiza el cerebro como factor que influye en la conducta. Nos referimos al campo del Periodismo que investiga a partir de la condición humana del individuo, según sus necesidades.

El periodista es observador de la realidad de los hechos, de sus competencias e intereses. Construye su percepción de acuerdo a los moldes sociales predeterminados acordes al progreso social y cultural que considera la regla informativa ${ }^{16} \mathrm{del}$ Periodismo emotivo. Activismo que distingue el conocimiento pleno
12 Entre las acciones no convencionales se encuentran: los actos testimoniales de expresión física o cultural (encierros, huelgas, etc.), la obstrucción de actividades ajenas (bloqueo del tránsito, sentadas, etc.), Pintadas de protesta, boicot de servicios o productos, resistencia al cumplimiento de obligaciones legales, manifestaciones ilegales o huelgas salvajes y destrucción o deterioro de bienes públicos y agresión contra personas. Hay que tener en cuenta que "lo no convencional de hoy puede ser lo convencional de mañana". Lo que separa a unas, con respecto de otras es la valoración social que varía según el tiempo. Un claro ejemplo son: "las huelgas prohibidas y reprimidas hasta bien avanzado el siglo XIX y reconocidas luego como un derecho fundamental (...). Hasta la década de los sesenta del siglo XX, la ciencia política no tuvo demasiado en cuenta a las "lamadas formas no conven-cionales" (Vallés, 2002: 232,324).

13 Opera "sintagmáticamente y paradigmáticamente". Tiene en cuenta convenciones en función "al uso que nosotros hacemos del texto espectacular... como código social, como conjunto de reglas y como repertorio de signos" (Sánchez, 2006, p. 369).

${ }^{14}$ Visto como un repertorio cultural es una "caja de herramienta de hábitos, técnicas y estilos con los cuales la gente construye estrategias de acción" (Even-Zohar, 1999:31,32).

${ }^{15}$ Examinamos la diferenciación sistémica de acuerdo a los límites definidos entre las ciencias y como elementos abiertos de demarcación. Las unidades comunes son tratadas como "medios propios del sistema" que no sólo se adaptan a su entorno, sino a su propia complejidad a través de los procesos de "diferenciación interna del sistema" respetando la dependencia de cada uno de ellos (Luhmann, 1990, p. 101).

${ }^{16}$ La regla informativa se constituye dentro de la estructura de la información del periodismo especializado. 
del sujeto en cuanto receptor, y no precisamente por la actividad sociocultural, política y educativa que pueda realizar, sino, en el estudio del sujeto en si mismo, por medio del cerebro racional y emocional. Característica informativa que podría ser aplicada en las diferentes especializaciones periodísticas, es decir, nos referimos a la construcción de sistemas códicos adaptados a la comprensión humana.

\section{La información próxima en la política}

La información periodística se encuentra sedimentada bajo tres funciones de vital importancia: informar, entretener y educar. Son tres principios que el periodista debe tener en cuenta en el momento de transmitir el hecho noticioso al ciudadano utilizando la libertad del medio.

Expuesta dicha premisa, relacionamos las funciones de informar y entretener dentro de sus límites y a través de su vinculación sistémica con el criterio de lograr una información más próxima y cercana al receptor, y constituimos a modo de convivencia simbiótica de ambos, la función de la información espectacularizada. Se realiza en función del criterio: "informar a través de entretener" considerando la trascendencia del hecho y la selección que establezca cada medio de acuerdo a sus intereses.

Se forma por medio de técnicas y de contenidos de entretenimiento, en consideración con la espectacularización y estructura de la información especializada. Proceso de transcodificación y traducción informativa que le ayuda a instituirse como una función periodística. Particularidad informativa del Periodismo emotivo.

Acercamos el hecho hasta el espectador reconociendo las singu- lares actitudes del hombre. Se puede adaptar el saber a modos de entender el público utilizando técnicas de representación que se derivan de la reducción de los hechos a categorías simples y atractivas, y a su vez, ficticias. Por ello es necesario adecuarlos, siempre y cuando se lleven al límite.

Es importante que los agentes noticiosos aparezcan caracterizados como personajes envueltos en conflictos. Política comunicativa redefinida como un eslabón en el sentido físico y simbólico que trata de crear cierto suspense y personalidad sobre su resolución a través de experiencias próximas. Clave comunicativa que permite mantener la atención del sujeto receptor.

En España la información política logra retener a la audiencia, sólo cuando los hechos se tornan en espectaculares. Se apoya del surgimiento de las alteraciones importantes en el gobierno o en el desenfreno de los agentes políticos.

Está comprobado que, en la vida diaria, la información política tiene gran éxito en momentos extremos de trepidación o de gran espectacularización de los acontecimientos, de ahí que la atención del sujeto receptor suele ser ocasional.

La transformación de la información política llega a ser el resultado de un proceso asentado en la espectacularización que, en ocasiones tiende a equipararse con espectáculos de entretenimiento o deportivos, pues su lógica temática necesita reconocer movimientos no convencionales. La influencia implícita se da cuando los fenómenos políticos apelan a las emociones del individuo, dando preferencia a lo inusual y a lo conflictivo a nivel cognitivo.

La ciencia política tiene como faena la identificación de las actitudes, así como el grado de intensidad según su medición que, permitirá 
elaborar una escala de actitudes, entre ellas, distinguimos cuatro categorías, cada cual con su "equipaje mental con que se pertrecha un ciudadano cuando interviene en política", nos referimos a las orientaciones cognitivas, afectivas, valorativas e intencionales. El sujeto integra y vincula cada una de estas disposiciones generando a su vez, "conocimientos, creencias, emociones y valoraciones, que van a producir determinadas conductas relacionadas con la esfera de la política" (Vallés, 2002: 247-251).

La conducta del individuo más que, procesos de creencias, son experiencias e instintos combinados con la reflexión y el principio que le regenta su actuar, nos referimos al sinequismo ${ }^{17}$. Visto desde la generalidad, es ley, desde el "esquema de la tríada de categorías peirceanas, terceridad $^{18}$, y está presente en el universo" (Barrena, 2001).

Dentro del análisis evolutivo del universo, la tendencia del individuo es la de formar hábitos, lo que le permite la regularidad en el conocimiento a nivel metacognitivo y por tanto, su comunicación. De ahí que es posible hablar de signo siempre y cuando medie en la mente humana como una ley de acción.

El ciudadano puede aceptar o rechazar diferentes actitudes, según sus orientaciones. El claro ejemplo es la "interrupción del tráfico organizada por un grupo ecologista que protesta contra la contaminación producida por el exceso de transporte privado" ó la figura de un actor político, ambos llegan a ser acogidos con ciertas valoraciones emotivas de aceptación o rechazo (Vallés, 2002: 247-251).

La función de la información espectacularizada dentro de su contextura considera el término de área bajo el nombre de espectacu-larización para ordenar los contenidos dentro de éste y asimismo, sumarle las áreas reconocidas dentro de la especialización del Periodismo como: la política, la educación, la economía, etc. (Sánchez, 2006: 248)

Dicho esto, el bloque informativo tratará contenidos especializados sobre el individuo "historias de cada día". Se afianza en el comentario y la crítica que considera la sobreinterpretación con el fin de lograr un adecuado tratamiento informativo y sobre todo de controversia propio de la función periodística de la información espectacularizada, en relación con su especialización (IEE) ${ }^{19}$.

Pretendemos pues, que los contenidos temáticos atraigan al sujeto receptor a los hechos cercanos añadiéndole elementos inusuales en el contexto narrativo de la noticia, según la estructura de IEE, con el fin de reconocer cómo se produce en la política la información próxima. Dicho esto, abordamos de forma práctica el siguiente enunciado: información especializada en la espectacularización (IEE) + información especializada en política $($ IEP $)=$

$$
\begin{array}{lc}
\begin{array}{l}
\text { Información } \\
\text { especializada } \\
\text { espectaculizada. IEE }
\end{array} & \text { P Área de especialización } \\
\text { Política } & \\
\begin{array}{l}
\text { Temas del individuo, } \\
\text { acción } \\
\text { historia de cada dia. }
\end{array} & \text { individual } \\
\begin{array}{|c|}
\text { La sobreinterpretación, } \\
\text { toral }
\end{array} & \text { + Tema: processo elec- } \\
\hline
\end{array}
$$

La función de la información especializada en la espectacularidad tiene en cuenta, en este caso, el área de la política. El bloque se estructura en relación con la política de acción individual teniendo en cuenta el tema sobre el proceso electoral.

El bloque informativo versa sobre el transcurso de una acción individual como una forma de intervención que va desde lo inadvertido hacia los comporta-mientos más espectaculares. Se trata de hechos coordinados que fomenten la participación ciudadana, por medio de
${ }^{17}$ Tendencia a formar hábitos como constructores de los principios de acción que "actualizan las posibilidades y encarnan el ideal de la razonabilidad constituyendo el medio del crecimiento" (Barrena, 2001).

${ }^{18} \mathrm{El}$ hecho de hablar del sistema triádico nos lleva a señalar las tres categorías de Peirce: Primeridad, segundidad y terceridad, esta última definida con los términos de mediación, de transformación y de evolución que marca el desarrollo de los signos. Se ha de unir con su objeto por medio de la mente y a través de las convenciones que posteriormente llevarán a la producción de símbolos que crean interrelaciones triádicas (Merrell, 2001).

${ }^{19}$ Significa información especializada en la espectacularización. 
asociaciones o colectivos.

Utiliza los géneros críticos del Periodismo emotivo por medio de la sobreinterpretación, con el criterio de lograr controversia sobre el tema en cuestión, en este caso, el proceso electoral. El individuo cuando se dirige a la mesa de sufragio a realizar su voto cumple dos significativas funciones, por un lado hablamos de una conducta y decisión individual y por otra, de un accionar colectivo del hombre como actor político desde que vive en su comunidad, es decir, se trata del comportamiento público asumido a nivel cognitivo.

El impacto de los medios a partir de las unidades emocionales, así como la capacidad de mediación pública por parte de algunos actores políticos, nos llevaría hablar del comportamiento del individuo como actor político y como elemento de observación que distingue diversas noticias en relación con otros procesos de información política, es decir, formas distintas de hacer política donde prime lo cercano al sujeto sobre la construcción de una información próxima por paradigmas códicos de inferencia abductiva en relación consigo mismo y adaptados a la comprensión del hombre.

\section{Abstract}

The related principle of politics to news settles they infer in the use of the technique, the structure and the process as systems that pick us, transmit, convey and observe a sequence of conducts in the individual. These are ways to talk politics and to transmit it according to its individual or collective action and its turn it gives rises to spectacular behaviours. The freedom of Media is in the construction of the near information by code paradigms adapted to the human comprehensiveness through emotional metacognitive process and adducing indifference, according to its experiences and sinequismos.

Key words: Politics, journalism, emotive nature, information, Media.

Bibliografía
BAR, Aníbal (2001): "La inferencia del descubrimiento" en Revista electrónica Moebio $n^{0} 12$. Accesible en [http://www.moebio.uchile.cl/12/bar.ntm] (consultado el 5 de febrero de 2007)

BARRENA, Sara (2001): "Los hábitos y el crecimiento: una perspectiva peirceana"en Razón y palabra, $n^{0} 21$ febrero-abril. Accesible en [http://www. razonypalabra.org.mx/anteriores/n21/index.html] (consultado el 14 de febrero de 2007)

BECHELLONI, Giovanni (1990): “¿Televisiónespectáculo o televisión- narración?”, en AA.VV.: Videoculturas de fin de siglo. Madrid: Cátedra, $\mathrm{p}$. 55-63.

BEZUNARTEA, Ofa y CANGA LAREQUI, Jesús (1989): Los límites de la información política. Las nuevas ofertas de TV privada en el estado español. San Sebastián: Universidad del País Vasco.

EVEN-ZOHAR, Itamar (1999). "Factores y dependencias en la cultura" en DIMIC, M. V. (et al). Teoría de los Polisistemas. Madrid, Arco, p. 23-52 FERNÁNDEZ DEL MORAL, Javier y ESTEVE RAMÍREZ, Francisco (1996): Fundamentos de la información periodística especializada. Madrid: Síntesis.

GOLEMAN Daniel (1997): Inteligencia emocional. Barcelona: Kairós.

HERRERO AGUADO, Carmen (1996): Periodismo político y persuasión. Madrid: Actas.

LÓPEZ, Antonio y GUERVÓS, Javier de Santiago (2000): Retórica y comunicación política. Madrid, Cátedra.

LUHMANN, Niklas (1990): Sociedad y sistema: la ambición de la teoría. Barcelona: Piadós.

MAYOR, Juan; SUENGAS, Aurora y GONZÁLEZ, Javier (1993). Estrategias metacognitivas: aprender a aprender y aprender a pensar. Madrid: Síntesis. MERRELL, Floyd (2001): "Charles Peirce y sus signos" en Signos en Rotación, Año III, n 181. Accesible en [http://www.unav.es/gep/Articulos/SRotacion3.html] (consultado el 14 de febrero de 2007).

SÁNCHEZ, H. Miluska (2006): El Periodismo emotivo. Una aproximación al mensaje televisivo. Sevilla, Equipo de Investigación de Análisis y Técnica de la Información.

VALLÉS, Joseph M. (2002): Ciencia Política: una introducción. Barcelona: Ariel.

Data do recebimento: 29/05/2007

Data do aceite: 03/07/2007 
Esquema $^{20}:$ La construcción de la información próxima en la política
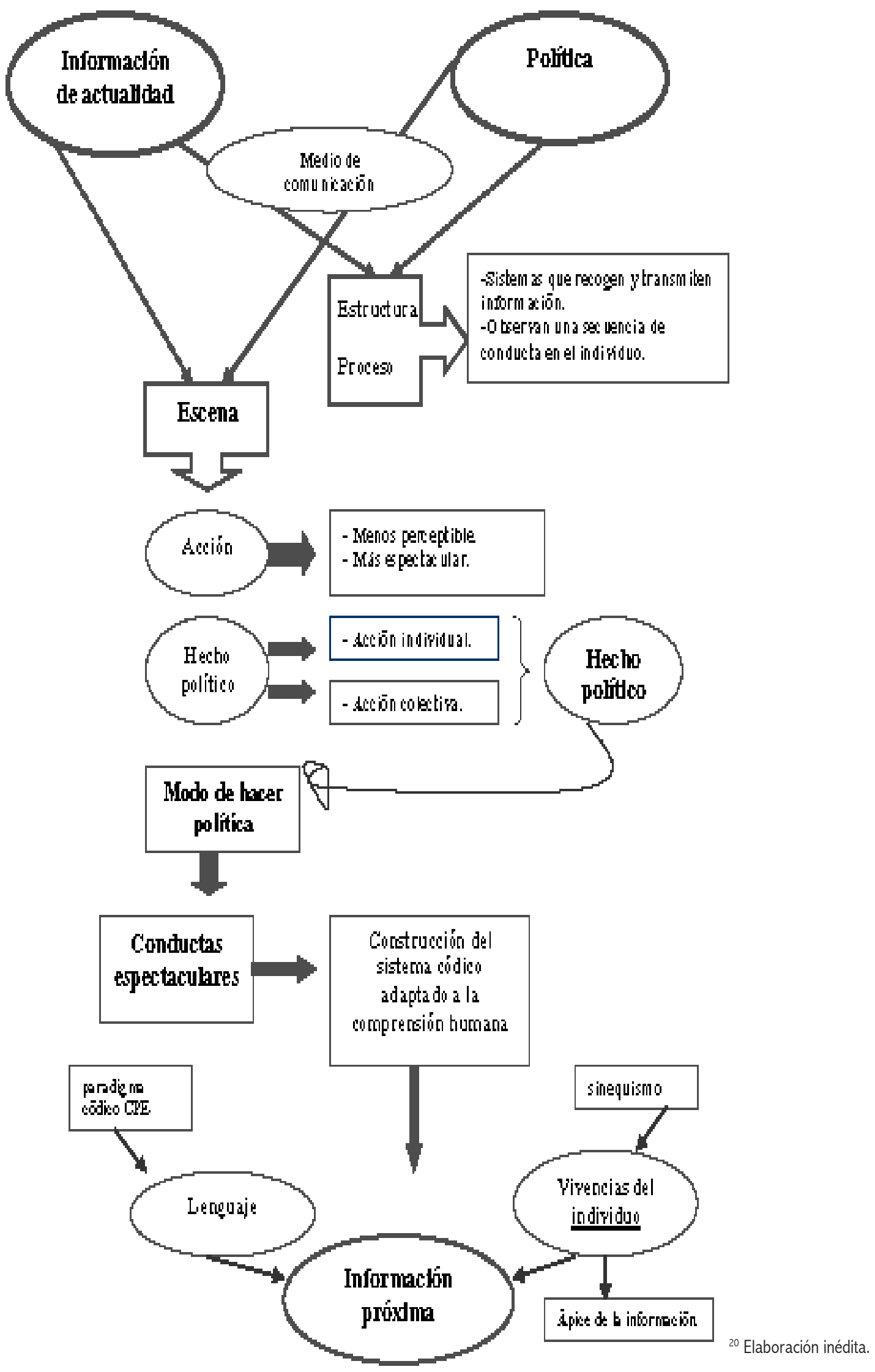